\title{
PROMOVENDO INSTITUIÇÕES EFICAZES, CENAS DA UNIDADE DE TERAPIA INTENSIVA: a morte e o morrer, sob o olhar do profissional de enfermagem \\ DOI: 10.22289/2446-922X.V5N1A1
}

\author{
Holivondi Sancho Pereira Neto ${ }^{1}$ \\ Breno Nunes Caixeta \\ Hugo Christiano Soares Melo \\ Gilmar Antoniassi Junior
}

\section{RESUMO}

Objetivo: conhecer a partir das experiências vivenciadas em ambientes intensivos de cuidados da saúde, como os profissionais de enfermagem lidam com a morte. Método: Trata-se de um estudo de campo do tipo qualitativo transversal de natureza exploratória, com profissionais de enfermagem que atualmente exercem a função em ambientes intensivos. Resultados: Estudo evidenciou que dos 6 (seis) participantes, todos necessitam de atenção para com a sobrecarga do luto; no entanto 3 (três) dos participantes tiveram indicadores que apontam para a necessidade de cuidados indicando a presença pouco mais intensa. Considerações: Se faz necessária um acompanhamento psicológico para os enfermeiros atuantes dentro das UTI's e que as faculdades de graduação em enfermagem possam investir em grades curriculares que permitam a preparação do acadêmico para a vivencia dentro do âmbito hospitalar, permitindo assim discussões sobre a temática morte e morrer de pacientes.

Palavras-chave: Ambientes; UTI; Enfermagem; Morte.

\section{ABSTRACT}

Objective: to know from the experiences lived in intensive health care environments, as the nursing professionals deal with death. Method: This is a cross-sectional qualitative crosssectional study, with nursing professionals currently working in intensive environments. Results: Study showed that of the 6 (six) participants, all need attention to the overload of mourning; however, three (3) of the participants had indicators that indicate the need for care indicating a little more intense presence. Considerations: It is necessary to provide a psychological follow-up for nurses working in the ICUs and for nursing undergraduate colleges to invest in curricular grades that allow the preparation of the academic to live within the hospital environment, thus allowing for discussions on the theme of death and dying of patients.

Keywords: Environments; ICU; Nursing; Death.

\footnotetext{
${ }^{1}$ Endereço eletrônico de contato: holivondispn@yahoo.com.br

Recebido em 05/11/2018. Aprovado pelo conselho editorial para publicação em 01/04/2019.
} 


\section{INTRODUÇÃO}

As unidades de terapia intensiva (UTI) foram criadas após a necessidade do paciente que se encontra em um estado de saúde mais crítico o qual necessita de assistência continua e com profissionais disponíveis em tempo integral do dia e da noite. Um modelo embasado aos cuidados destinados aos soldados feridos gravemente na guerra da Criméia em meados do século XIX em Florence (Lino \& Silva, 2001)

O trabalho que envolve a UTI é complexo e continuo, a equipe ali envolvida deve estar preparada para lidar com situações onde as intervenções necessitam serem rápidas e eficazes. Gomes (2000), ressalta que os cuidados prestados aos pacientes intensivos e críticos torna-se eficiente quando desenvolvidos com agilidade, especialmente por parte do enfermeiro, quando a função é de cuidar, educar, coordenar, colaborar e supervisionar (Cedenési et al. 2012).

Os equipamentos presentes dentro das UTI's possibilitam um cuidado mais avançado unindo tecnologia e conhecimentos específicos e generalizados, colocando o enfermeiro frente a ações de integrar tecnologia ao cuidado individual do paciente e suprindo as necessidades essenciais, terapêuticas e fundamentais do paciente. (Vargas \& Braga, 2013). O que requer do profissional de enfermagem educação permanentemente para aprimorar conhecimentos ante ao estado de saúde e doença, facilitando na tomada de decisões diante do processo de cuidar. Por certo, a educação em saúde desempenha um papel primordial dentro do âmbito hospitalar, tanto na relação entre a equipe multidisciplinar quanto a relação equipe/paciente realizando a transformação do cuidado e a disseminação dos conhecimentos específicos de toda equipe. Dentro da unidade de terapia intensiva (UTI) o paciente perde sua autonomia diante do próprio cuidado, não opinando de forma totalizada durante alguns procedimentos realizados, da própria higiene e de costumes rotineiros, essa perca de autonomia pode se prolongar após a alta do paciente, sendo assim, o enfermeiro que possui a função de educar tem a responsabilidade de orientar o paciente e seu respectivos familiares sobre o autocuidado, levando a preservação do seu bem estar em casa (Cedenési et al. 2012).

Dentre as diversas funções exercidas pelo enfermeiro na UTI, a principal desempenhada são os cuidados, contudo, o enfermeiro atua também na de coordenação do setor, na colaboração de atividades inerentes ao cargo e na supervisão da sua equipe, técnicos e auxiliares, na tomada de decisões relacionadas ao cuidado do paciente, sendo todas importantes para manter a interpelação positiva no ambiente, todas essas funções são interligadas, podendo em alguns casos colocar em práticas mais uma que outras sendo que todas são importantes e sustentáveis para suas práxis diárias (Cedenési et al. 2012; Alencar et al. 2004; Backes, Erdmann \& Buscher, 2015).

Ainda assim, o enfermeiro é a ligação entre família, paciente e equipe de unidade. Não obstante, o enfermeiro atuante em uma UTI sofre constante pressão, pois, é um setor da unidade 
hospitalar ao qual lida constantemente com a angustia da família e da equipe em relação a vida e a morte. Todavia, apesar de existir a equipe multiprofissional, é o enfermeiro que possui o contato direto com o paciente, fazendo com que toda sua equipe esteja entrosada a manter o equilíbrio vital do alojado (Alencar et al. 2004).

Batalhar pela vida é um dos objetivos primordiais daqueles que trabalham nas UTI's, priorizando tratamentos adequados a situação de recuperação do estado de vida do paciente. $O$ ambiente da UTI é propício a salvar vidas e estabelecer o estado vital, conquanto, quando ocorre a morte de internados dos alojamentos, os profissionais ficam frustrados e angustiados devido a sensação de ineficiência em não conseguir recuperar a saúde, o estado de vida (Backes, 2011). Levando aos profissionais envolvidos a e inutilidade por não alcançar os objetivos determinados, podendo assim, alguns profissionais evitarem se relacionar de forma mais intimista com os familiares do paciente por medo da reação dos mesmos quando ocorrer o óbito do ente querido (Backes, Erdmann \& Buscher, 2015).

Segundo Amestoy et al. (2006), alguns profissionais de enfermagem negam um envolvimento emocional mais profundo com pacientes e seus familiares, pois quando o contato é maior entre enfermeiro e paciente e esses veem a óbito o profissional tende a sofrer. Qualquer contato com uma pessoa em estado de saúde terminal, que se cria um laço ou vínculo afetivo na relação entre paciente e profissional, enfrentar a morte desses é uma tarefa árdua e difícil para os profissionais de enfermagem que trabalham na UTI; pois, essa perda acarreta reações emocionais que podem vir prejudica-los nas suas atividades no âmbito hospitalar, e afetar o convivo social externo ao ambiente de trabalho (Filho et al. 2001).

Por conseguinte, a Organização das Nações Unidas [ONU] (2015) assegura por meio da agenda 2030 no objetivo 16 ações que promova sociedades pacíficas e inclusivas para o desenvolvimento sustentável (ODS), proporcionando o acesso à justiça para todos, afim de construir instituições eficazes, responsáveis e inclusivas em todos os níveis de saúde na sociedade.

Nesta lógica, pensar a relação entre a morte e o profissional de enfermagem nos ambientes intensivos, requer olhar para como os profissionais de enfermagem lidam com as cenas de morte quando inseridos no ambiente da unidade terapia intensiva. Por acreditar que o profissional de enfermagem lida diariamente com a morte passa por momentos de pressão diante as cenas de perdas ocorridas em ambientes intensivos de seus pacientes, podem assim, afetar sua afetividade e os modos em que lidam no cotidiano rotineiro da vida. Visto que, o objetivo 16 da ODS tem como uma de suas metas desenvolver instituições eficazes, responsáveis e transparentes visando a promoção do Estado de Direito garantindo a igualdade de acesso à justiça, a tomada de decisão responsiva, inclusiva, participativa e representativa em todos os níveis e para todos, seja no estado de vida e morte, bem como, no cuidado da equipe de prestação de serviço de saúde (Organização das Nações Unidas [ONU], 2015). 
Assim, o presente estudo objetiva-se em conhecer a partir das experiências vivenciadas em ambientes intensivos de cuidados da saúde, como os profissionais de enfermagem lidam com a morte.

\section{MATERIAS E MÉTODOS}

Trata-se de um estudo de campo do tipo qualitativo transversal de natureza exploratória, com profissionais de enfermagem que atualmente exercem a função em ambientes intensivos. O qual foi realizado em um Hospital Geral de uma cidade da Região do Alto Paranaíba, estado de Minas Gerais, Brasil, que atende aproximadamente uma população de 149.856 pessoas, segundo dados do IBGE (Brasil, 2017).

A amostra foi composta de modo intencional, por meio de convite direto aos profissionais de enfermagem, o qual demonstrarem interesse será convidado a participarem das entrevistas e preencherem a escala. Sendo inclusos aqueles profissionais que atualmente trabalham na UTI, com mais de 2 (dois) anos de atividade no setor e maiores de 18 anos; e exclusos aqueles que não atenderem aos critérios de inclusão, e deixarem de participar de alguma etapa da pesquisa e/ou rasurar os instrumentos; participando 6 enfermeiros.

O estudando atendeu-se aos princípios éticos segundo as Resoluções do CNS №.466/2012 e №. 510/2016 para pesquisa com seres humanos, sendo submetido ao Comitê de Ética em Pesquisa da Faculdade Patos de Minas sendo aprovado sob parecer 2.984.327 (Anexo A), e com anuência da Direção do Hospital (Anexo B).

Como instrumentalização de pesquisa utilizou-se da Entrevista Semiestrutura Livre e da Escala de Sobrecarga do Luto Profissional. A entrevista foi composta por disparadores de pensamento classificados em campos investigativo de: Como você percebe a morte? Sobre a morte, como você lida com ela diariamente? Acredita que ela tenha afetado seus sentimentos? O que você acha necessário em termos de cuidado com o profissional que lida com a morte? Durante o período de graduação (formação) você teve alguma disciplina que permitiu debater estes aspectos? Como você vê este período? Como você lida com os sentimentos de perca na sua vida? A proximidade com as percas decorrentes da morte, afetou você ocasionando danos psicoemocionais? E a escala sobrecarga do luto profissional foi desenvolvida por Gama, Barbosa e Vieira (2011), e tem por finalidade ajudar o profissional de saúde prevenir estados de sofrimentos elevados, procurando avaliar a intensidade do luto insulado nos profissionais de saúde expostos ao processo de morte e morrer diariamente. Contendo 15 questões podendo ser respondidas em escala tipo Likert classificados em cinco (5) categorias (1, discordo fortemente; 2, discordo; 3, concordo um pouco; 4, concordo; 5 , concordo fortemente).

Para coleta de dados primeiramente deu-se com a visita aos profissionais de enfermagem que corresponde a equipe de enfermagem na UTI da instituição hospitalar; foi realizado um 
levantamento junto ao coordenador da unidade para mapear aqueles membros aos quais corresponde ao critério de inclusão por tempo de serviço na unidade. Logo foi agendado um encontro com os profissionais identificados, aos quais foram convidados a participarem do estudo, sendo apresentado Termo de Consentimento Livre e Esclarecido (TCLE) contendo o objetivo do estudo e a proposta. Após aqueles que se dispuserem a participarem e as dúvidas forem esclarecidas, solicitou a assinatura no TCLE.

Primeiramente, foi aplicada a escala de sobrecarga de luto, por se tratar de um instrumento de aplicação coletiva, os participantes receberão as instruções de preenchimento da escala, em que ocorreu em uma sala ampla, arejada e isolada, o que possibilitou aos participantes não sofrer influencias externas e tenha condição de refletir sozinho. Foi-se resguardado ao pesquisador uma mesa de fácil localização para esclarecimento de dúvidas no preenchimento. Após o preenchimento da escala, cada participante depositou sobre a mesa a escala respondida, e juntos enveloparam e lacraram; dando sequência foi agendado o encontro para a entrevista.

As entrevistas ocorreram separadamente, na mesma sala de aplicação da escala, em dias diferenciados, não havendo limite de tempo para o diálogo estabelecido, durando aproximadamente 3 horas. Primeiramente, foi estabelecido o rapport, afim de criar uma ligação de sintonia e empatia com o participante. Logo, foi disparado o primeiro questionamento reflexivo, e assim, por conseguinte. No final da entrevista, foi questionando ao participante se o mesmo se deseja atendimento com os estagiários de Psicologia da Clínica Escola conforme compromisso no estudo descrito no TCLE, não havendo interessados.

Para as análises, as entrevistas foram gravadas em áudio, com utilização de gravador digital, e transcritas na integra. Utilizando-se da análise de conteúdo para a compreensão do fenômeno e os modos de se relacionar. Para a escala de sobrecarga do luto profissional levará em consideração a padronização de aferição do instrumento. Considerando, a somatória total dos itens salienta-se que, quanto maior a pontuação obtida, maior o nível de sobrecarga de luto profissional, a ser classificados quanto ao Fator 1 foi designado "Confinamento atormentado"; integra 7 itens $(2,5,6,10,12,13,14)$, refere-se a situações em que o profissional de saúde, exposto a perdas múltiplas cumulativas, manifesta uma restrição na sua vida pessoal, limitando os contatos com a família e os outros, não se dando tempo a si próprio, com preocupações frequentes sobre as perdas de doentes que estiveram ao seu cuidado e sentimento de ter a vida encarcerada, sem liberdade devido às responsabilidades e exigências profissionais. $O$ fator 2 foi designado "Esforço emocional no cuidar", integra 3 itens $(8,9,15)$, refere -se à dor mental ou às dificuldades emocionais sentidas que ocorrem no cuidar destes doentes em fase terminal comparativamente com outros tipos de doentes. O fator 3 foi designado "Perda nostálgica", integra 2 itens $(1,4)$, refere -se aos sentimentos de ausência, saudade e/ou vazio relativo aos doentes falecidos. O fator 4 foi designado "Partilha incompreendida", integra 3 itens $(3,7,11)$ refere -se à dificuldade ou impossibilidade de validação ou legitimação dos sentimentos 
experimentados pelo profissional na sequência da morte dos seus doentes, por familiares, amigos e colegas (Gama, Barbosa \& Vieira, 2011).

\section{RESULTADOS}

Em relação aos participantes da entrevista $50 \%(n=3)$ são enfermeiros e $50 \%(n=3)$ são enfermeiras, com idade entre 25 a 40 anos e entre 2 a 10 anos de formado.

Em relação a Escala de Sobrecarga do Luto Profissional os dados revelam que dos 6 (seis) participantes, todos necessitam de atenção para com a sobrecarga do luto; no entanto 3 (três) dos participantes tiveram indicadores que apontam para a necessidade de cuidados indicando a presença pouco mais intensa; a tabela 1 permite identificar os indicadores.

Tabela 1. Indicadores da presença da sobrecarga do luto profissional nos enfermeiros participantes do estudo.

\begin{tabular}{ccc}
\hline Participante & Escore Total & Consideração \\
\hline Sujeito 1 & 38 pontos & Presença Sobrecarga - necessidade de cuidado \\
Sujeito 2 & 39 pontos & Presença Sobrecarga - necessidade de cuidado \\
Sujeito 3 & 34 pontos & Presença Sobrecarga - necessidade de atenção \\
Sujeito 4 & 38 pontos & Presença Sobrecarga - necessidade de cuidado \\
Sujeito 5 & 35 pontos & Presença Sobrecarga - necessidade de atenção \\
Sujeito 6 & 35 pontos & Presença Sobrecarga - necessidade de atenção \\
\hline
\end{tabular}

A mesma escala revela que o fator de maior equivalência é o Confinamento atormentado (fator 1) seguido do esforço emocional (fator 2), onde influenciam de forma superior dos demais itens na lida dos entrevistados, já os fatores de perda nostálgica (fator 3) e partilha incompreendida (fator 4) são fatores que tem uma somatória menor, mas que ainda assim influenciam na vida dos enfermeiros.

De acordo com as entrevistas no que se refere sobre como os profissionais de enfermagem percebem a morte, evidenciou-se como algo normal, com momentos de dor e tristeza. Sobre como lidam com a morte, os mesmos relataram que no início foi um pouco difícil, mas que agora já se acostumaram.

"Algo natural, igual o nascimento, um ciclo da vida." (S1).

"Como um momento de dor e tristeza" (S2).

"Percebo ela como um acontecimento natural, todos nós iremos bater de frente com a danada um dia" (S3). 
Outro fator identificado refere-se sobre o afetamento da morte em relação aos próprios sentimentos, predominaram alguns relatos de que se sentem afetados com a morte de seus pacientes e que muitas vezes se fazem de durões para não sofrer.

"Acho que todo mundo acha ruim perder alguém, seja paciente ou parente, as vezes a gente finge de durão pra não sofrer tanto" (S3).

“...tornei uma pessoa mais tranquila, pode se dizer, para lidar com ela. ”(S1).

Sobre a formação acadêmica do profissional de enfermagem no tocante a morte no ambiente assistencial da enfermagem, quase todos confidenciaram que não tiveram nenhum preparo para lidar com o óbito, e quando surgia esta temática era relatos da vida pessoal de alguns colegas, mas nunca de uma forma profissional.

"Não tive não, mas acho que seria bom viu..." (S6).

"A gente conversa muito sobre a morte, mas de forma pessoal e acho que nunca falamos tanto sobre o profissional não! "(S5).

"Não tivemos nenhuma oportunidade de debater isso, acho que a gente só preocupa com nota e esquece um pouco o lado humano. " (S2)

A Entrevista revela também sobre como esses profissionais lidam com as percas na vida, seja pessoal ou profissional, que ainda se frustram, se chateiam e que a vida é assim, um dia ganhando e outro perdendo. Sendo assim os danos psicoemocionais decorrente da aproximação esses enfermeiros relatam que se tornaram uma pessoa mais fria, que em muitas vezes não pensam sobre e que em alguns casos se acostumam ou tentam se acostumar.

"Um dia todo mundo perde, no outro ganha e assim a gente vai indo" (S1).

"Acho que sim, a gente fica mais seco conforme o passar do tempo" (S2).

"Sem sombra de dúvidas... Quando a gente ver alguém morrendo, a gente valoriza a vida! $"(S 4)$

\section{DISCUSSÃO}

Segundo Gama et al. (2011) os profissionais de enfermagem atuantes em unidades de terapia intensiva são expostos a mortes e perdas frequentes, tendem assim a sofrer uma sobrecarga do luto, o que se evidenciou na tabela 1 , no qual $50 \%$ dos enfermeiros estão com presença de sobrecarga e os outros $50 \%$ possuem uma necessidade de atenção. 
De acordo com os dados, pode-se afirmar que os enfermeiros percebem a morte como algo natural evidenciado nas falas dos mesmos: (para mim é algo natural) $\mathrm{S1}$, (um momento de dor e tristeza) S2, isso corrobora a literatura que, segundo Cecagno (2009) que os enfermeiros percebem a morte como um momento doloroso, pois mostra a fragilidade humana.

Ressalta também nos resultados que os participantes evitam um contato mais profundo com os pacientes ou pensam de uma forma mais intensa sobre a sua morte, fato confirmado na fala do S4 (Tento não pensar muito sobre, porque se a gente pensar a gente fica doido), algo que atesta a fala na qual Amestoy et al. (2006), afirma que alguns profissionais negam um envolvimento emocional com pacientes porque quando eles chegam a óbito o profissional tende a sofrer.

Os resultados também apontam para uma falta de abordagem mais profunda durante a graduação, afirmado nas falas quando perguntados sobre a formação acadêmica: Tiveram um preparo durante a graduação para lidar com a morte? (Não tive não...acho que seria bom.) S4, o que pode ser apontado na fundamentação discutida em Bandeira (2014) no qual ressalta que a graduação ainda continua a preparar de forma insuficiente seus acadêmicos para lidar com a morte e o morrer.

Outro aspecto relevante achado durante a pesquisa é que os profissionais de enfermagem que atuam dentro das unidades de terapia intensiva ainda se frustram com as perdas, seja elas de pacientes ou não, acontecimento discutido por Amestoy et al. (2006) em que afirma que o sentimento de impotência cai sobre os profissionais de enfermagem pelo fato de serem preparados para salvar vidas, com objetivo de prolongar ou melhorar a expectativa dos pacientes/familiares e quando isso ocorre se frustram e se sentem incapazes.

\section{CONSIDERAÇÕES FINAIS}

A morte dentro do dia a dia da enfermagem está sempre presente, um acontecimento que mexe com os sentimentos dos profissionais. Percebeu que ainda existe uma dificuldade em se falar e em lidar com a morte, por ser um processo tenebroso que envolve crenças, tradições e diferentes opiniões.

O objetivo desta pesquisa se tratou em identificar as experiências vividas pelo enfermeiro dentro da sua lida na UTI, sendo assim ficou evidenciado que os enfermeiros possuem uma sobrecarga de luto profissional, por encarar diariamente o processo de morte e morrer de seus pacientes, levando em consideração que muitos negam um envolvimento mais intimista por medo do sofrimento se caso esse usuário vier a óbito, observado a necessidade de preservar a sua saúde psicoemocional.

Fica explicito que o profissional de enfermagem tem a necessidade de uma atenção sobre a sua saúde mental, que as faculdades de graduação em enfermagem possam estabelecer uma 
comunicação mais forte e intima dentro da sua grade curricular, orientando seus acadêmicos sobre o processo de morte e morrer e preparando-os para dura realidade dentro do âmbito hospitalar. Propiciando aos acadêmicos experiências e reflexões sobre a temática.

Conclui-se que ainda existem algumas lacunas que precisam ser corrigidas dentro da graduação, possibilitando um entendimento possa se de que a responsabilidade da morte não é da sua equipe e sim u processo natural da vida. E que os profissionais atuantes tenham um acompanhamento psicológico dentro da empresa que colabora, permitindo assim discussões e observações diante do processo de morte/morrer de seu paciente/familiar.

\section{REFERÊNCIAS}

Alencar, K. S., Diniz, R. C. M., \& Lima, F. R. F. (2004). Administração do Tempo nas Atividades de Enfermagem de uma UTI. Revista Brasileira Enfermagem, 57(4), 417-420.

Amestoy, S. C., Schwart, E., \& Thofehrn, M. B. (2006). A humanização do trabalho para os profissionais de enfermagem. Acta Paulista de Enfermagem, 19(4), 444-449.

Backes, M. T. S. A Sustentação da vida no ambiente complexo de cuidados em Unidade de Terapia Intensiva. Dissertação de Doutorado em Enfermagem, Universidade Federal de Santa Catarina, Florianópolis, SC.

Backes, M. T. S., Erdmann, A. L., \& Büscher, A. (2015). O ambiente vivo, dinâmico e complexo de cuidados em Unidade de Terapia Intensiva. Rev Latino-Am Enfermagem, 1(1), 1-8.

Bandeira et al. (2014). A morte e o morrer no processo de formação de enfermeiros sob a ótica de docentes de enfermagem. Texto Contexto Enferm, 23(2), 400-407.

Filho, L. W. D., Sulbach, R. C., \& Nunes, A. C. (2001). Percepções e condutas dos profissionais de enfermagem frente ao processo de morrer e morte. Texto \& contexto enferm, 10(3), 6081.

Gama, G. M., Barbosa, F., \& Vieira, M. (2011). Escala de sobrecarga do luto profissional (SLP). Revista cadernos em saúde, 4(2), 57-64

Grande et al. (2012). Funções desempenhadas pelo enfermeiro em unidade de terapia intensiva. Revista da Rede de Enfermagem do Nordeste, 13(1), 92-102.

Gomes, A. M. (2000). Enfermagem na Unidade de Terapia Intensiva. (5 ed.). São Paulo: EPU.

Instituto Brasileiro de Geografia e estatística. (2016). População Brasileira. Recuperado 15 outubro, 2018 from https://paises.ibge.gov.br/\#/pt/pais/brasil/info/populacao/

Lino, M. M., \& Silva, S. C. (2001). Enfermagem na unidade de terapia intensiva: a história como explicação da pratica. Revista Nursing, 4(41), 25-29.

Mattos et al. (2009). Profissionais de enfermagem e o processo de morrer e morte em uma unidade de terapia intensiva. Revista Mineira de Enfermagem, RME, 13(3), 456-461.

Organização das Nações Unidas. (2015). Agenda 2030. Brasil. Recuperado 15 outubro, 2018, from https://nacoesunidas.org/pos2015/agenda2030/

Vargas, D., \& Braga, A. L. (2013). O Enfermeiro de Unidade de Tratamento Intensivo: refletindo sobre seu papel. Rev FAFIBE Online, 1(1), 1-6. 